\title{
Gaps and patches in the ocean: a one-dimensional analysis of planktonic distributions
}

\author{
Warren J. S. Currie ${ }^{1, *}$, Michel R. Claereboudt ${ }^{2}{ }$ John C. $^{\text {Roff }}{ }^{1}$ \\ ${ }^{1}$ Department of Zoology, University of Guelph, Guelph, Ontario N1G 2W1, Canada \\ ${ }^{2}$ Groupe interuniversitaire de recherches océanographiques du Québec, Université Laval, Pavillon Vachon, \\ Ste. Foy, Quebec G1K 7P4, Canada
}

\begin{abstract}
The Optical Plankton Counter (OPC) was used to count individual animals in situ, and to produce a one-dimensional spatial-series from which gap relationships could be quantified at the millimeter scale and above, using a Distance to Next Encounter (DNE) technique. Both DNE and onedimensional neighbor analyses indicated that zooplankton distributions in all transects were significantly $(p<0.0001)$ aggregated into patches. Within patches, zooplankton were effectively $\left(r^{2} \approx 0.94\right)$ randomly distributed, resulting in important implications for some of the newer foraging models concerning zooplankton. The DNE frequency distributions all exhibited a distinct pattern that would not be expected from single Poisson distribution, indicating patchiness at the meter scale. This allowed calculation of various statistics used to describe in situ patchiness such as: relative percentage of a transect occupied by patches ( 79 to $89 \%$ ) and gaps, estimates of patch size ( $2 \mathrm{~m}$ diameter), and patch densities (7000 to 14000 organisms $\mathrm{m}^{-3}$ ).
\end{abstract}

KEY WORDS: Plankton Z Zooplankton Patchiness - Gaps Transect

\section{INTRODUCTION}

There can now be little surprise at the mention of the patchiness of planktonic organisms in the oceans. However, the study of these spatial relationships has focused almost entirely on scales which are large relative to the size of these animals. At the macro- and mesoscales (tens to thousands of meters), a variety of mechanisms or processes have been implicated as determining the distributions of organisms. These include tidal fronts (Franks 1992) internal waves (Shanks 1983, Lazier \& Mann 1989, Davis et al. 1991, Haury et al. 1992), stratification, diel vertical migration (Riley 1976, Hill 1991), and Langmuir circulation (Ledbetter 1979, Schneider \& Bajdik 1992).

Within this context of physical-biological interactions, little attention has been paid to the investigation of micro-scale patchiness $(<1 \mathrm{~m})$, the very smallest scales approaching the distances between individuals. The

•E-mail:wcurrie@uoguelph.ca interactions of physical and biological processes at these scales, and their extent and influence in the physically dominated pelagic environment is not yet understood. This deficiency is due to the requirement for a simultaneous knowledge of both the physical processes and the concomitant biological distributions. Although models of the interactions between individuals in aquatic communities have been created for feeding and encounter rates (Rothschild \& Osborn 1988, Yamazaki et al. 1991, Hwang et al. 1994, Kiørboe \& Saiz 1995), they have been developed without the support of empirical knowledge of spatial relationships of organisms at the appropriate scale. While some theoretical work has been accomplished on the microdistribution of organisms within plankton patches (Osborn et al. 1990, Rothschild 1992, Yamazaki \& Haury 1993), the investigations that were carried out have taken place in enclosures under laboratory conditions (Price 1989, Cuddington \& McCauley 1994, Leising \& Yen 1997).

In contrast, within terrestrial and benthic communities, the use of in situ transect sampling and the mea- 
surement and analysis of neighbor distances as a tool to describe and interpret spatial relationships among individuals is now well established due to the work of plant ecologists (Greig-Smith 1964. Pielou 1969, Southwood 1978). Such spatial relationships among individual organisms in pelagic aquatic communities are virtually unknown due to the inherent problems visualizing distributions in the open water. Conventional methods of sampling (e.g. plankton nets, traps, or pumps) integrate their collections either vertically or horizontally over relatively large scales; as a result they lack the resolution to gather single individuals, and their collection requires tremendous time and effort to analyze (Davis et al. 1992, Pinel-Alloul 1995).

The development of the in situ Optical Plankton Counter (OPC) allows us to count individual animals and, through a simple modification, to develop time/ spatial-series from which neighbor relationships can be quickly and easily quantified. This methodology allows a relatively unobtrusive determination of zooplankton spatial distributions from the $\mathrm{km}$ scale down to that of millimeters. Due to the three-dimensional nature of the sampling device and the one-dimensional nature of the output, the true nearest neighbor measures cannot be calculated; however the next value is known within the one-dimensional series. In recent years, this application of neighbor analysis from one-dimensional series has become well established (Selkirk \& Neave 1984, Shiyomi \& Yamamura 1993, Weingart \& Selvin 1995). In this paper we present a method of analyzing patch dynamics in planktonic systems using a one-dimensional Distance to Next Encounter (DNE) technique, from a spatial data series collected by the OPC.

\section{METHODS AND ANALYSIS}

OPC operation. The Focal Technologies Inc. OPC quantifies plankton abundance by measuring the optical surface area of individual zooplankters encountered along a transect in the water (Herman et al. 1992). As the OPC is towed in the water, plankton pass into a flow-through tunnel where they cross a thin rectangular light beam that measures the profile area of each individual target. The OPC thus provides in situ measurements of targets, ranging in size from $250 \mu \mathrm{m}$ to $20 \mathrm{~mm}$ in equivalent spherical diameter, at rates up to 200 counts per second. The electronic size of each particle was converted into Equivalent Spherical Diameter (ESD) using the manufacturer's OPC LabWindows ${ }^{\oplus}$ Data Acquisition Software. Particle counts at the towing speed (approx. $1.3 \mathrm{~m} \mathrm{~s}^{-1}$ ) ranged from 20 to 70 counts $\mathrm{s}^{-1}$ and never exceeded $80 \mathrm{~s}^{-1}$; this is well below the level at which coincidence counts would become significant ( $>200 \mathrm{~s}^{-1}$ ) (Herman et al. 1992).
At our request, the manufacturer modified the micro-controller of an OPC to add a time stamp with a $1 / 1000 \mathrm{~s}$ resolution to the data file, for each recorded particle. As a result, the data file contained the absolute time of encounter for each particle in addition to the existing data on particle size, index of light attenuation and in situ velocity from the device's onboard OMEGA FP-5200 velocity meter The OPC was coupled with a SeaBird-25 CTD profiler which stored synchronously collected information on temperature, salinity, light transmission, and oxygen concentration, and a Seatech fluorometer which collected in situ fluorescence.

The sampling devices were towed laterally at various fixed depths from 2 to $8 \mathrm{~m}$ in the near-shore region (bound by the $4 \mathrm{~m}$ and $35 \mathrm{~m}$ isobaths) of the St. Lawrence Estuary near Mont-Joli, Quebec, Canada $\left(48^{\circ} 40^{\prime} \mathrm{N}, 68^{\circ} 10^{\prime} \mathrm{W}\right)$, at various points of the tidal cycle during July and August of 1995. Transects were typically $1024 \mathrm{~s}$ in length $(4096$ sampling points for the CTD at $4 \mathrm{~Hz}$ ), or approximately $1700 \mathrm{~m}$ at $1.3 \mathrm{~m} \mathrm{~s}^{-1}$. A $250 \mu \mathrm{m}$ mesh plankton net was affixed to the outflow of the OPC for these samples to collect all particles passing through the device for counting calibration and taxonomic identification.

DNE calculation. DNE measures were calculated using a velocity value averaged over $10 \mathrm{~s}$. DNE is a simple statistic calculated from:

$$
\mathrm{DNE}=V\left(T_{1}-T_{1-1}\right)
$$

where $T_{1}$ is the time of encounter for the $i$ th particle and $V$ is the towing velocity. This value was calculated using all size categones of particles within the data sets. The one-dimensional neighbor technique of Selkirk \& Neave (1984) was also used to test the degree of patchiness of particle distributions as a whole. Briefly, this technique compares nearestneighbor $(\mathrm{N}-\mathrm{N})$ distances along a line transect to those expected due to a random distribution and requires no distributional assumptions. A N-N statistic greater than 0.5 indicates a tendency towards regular spacing, values below 0.5 represent a tendency towards aggregation in the distribution. In addition, we assessed the frequency distributions of the DNE values themselves. Given no bias in particle position when it enters the OPC, if the particles are randomly distributed along the space-time axis of the OPC, then the distance (time) between 2 successive particles should follow an exponential distribution; this would appear as a straight line on a log-frequency versus distance to next-encounter plot.

Various descriptive patch statistics were generated using an extension of Rothschild (1992), and a variety of other useful descriptors were also calculated to illustrate the nature of patchiness at the scale of the individual (Table 1). 
Table 1 Calculations for the various patch statistics listed in Table 2 of the Distance to Next Encounter technique for 11 transects using an Optical Plankton Counter (OPC)

\begin{tabular}{|c|c|}
\hline$A_{o p c}$ & OPC sampling surface area $=0.22 \times 0.02[\mathrm{~m}]$ \\
\hline$D$ & Total distance of transect $[\mathrm{m}]$ \\
\hline$V_{\mathrm{s}}$ & Total volume sampled $\left[\mathrm{m}^{3}\right]=D \times A_{o p c}$ \\
\hline$N$ & Total particles within patches $=\Sigma$ all particles \\
\hline$n_{1}$ & $\begin{array}{l}\text { Number of patches in the transect }=\sum \text { particles } \\
\text { within the 'second distribution' }+1\end{array}$ \\
\hline$n_{\mathrm{p}}$ & Number of patches per $100 \mathrm{~m}$ \\
\hline$n_{\mathrm{pp}}$ & Number of particles per patch $=N / n_{1}$ \\
\hline$d_{\max }$ & $\begin{array}{l}\text { DNE value for Iimit of the 'first distribution' (within } \\
\text { patch). (Refer to Fig. 2) }\end{array}$ \\
\hline$D_{1}$ & $\begin{array}{l}\text { Total transect distance taken up by patches }[\mathrm{m}]= \\
\sum_{0}^{d_{\max }} \text { (DNE) for within patch }\end{array}$ \\
\hline$P_{w / 1}$ & Percent of transect occupied by patches $=D_{\mathrm{p}} / D$ \\
\hline$G_{w_{11}}$ & Percent of transect forming gaps $=1-D_{\mathrm{p}} / D$ \\
\hline$\phi_{\mathrm{p}}$ & Estimated average linear patch size $[\mathrm{m}]=D_{\mathrm{p}} / n_{1}$ \\
\hline$V_{\mathrm{p}}$ & $\begin{array}{l}\text { Mean volume per patch assuming isotropic sphere } \\
{\left[\mathrm{m}^{3}\right]=\frac{4}{3} \pi\left(\phi_{y} / 2\right)^{3}}\end{array}$ \\
\hline & Linear density [organisms $\mathrm{m}^{-1}$ ] $=n_{\mathrm{pp}} / \phi_{\mathrm{p}}$ \\
\hline & Mean patch volume sampled $\left[\mathrm{m}^{3}\right]=o_{p} \times A_{o p c}$ \\
\hline & Within patch density lorganisms $\mathrm{m}^{-3} \mathrm{I}=n_{\mathrm{pp}} / V_{\mathrm{sp}}$ \\
\hline & Overall average patch density [organisms $\left.\mathrm{m}^{-3}\right]=N / V_{\mathrm{s}}$ \\
\hline
\end{tabular}

The one-dimensional neighbor distance statistic (Selkirk \& Neave 1984) indicated that individual particle distributions in all the transects were significantly nonrandom ( $p<0.0001$, Table 2). The individual N-N values were significantly $<0.5$, ranging between 0.3667 and 0.4143 , indicating that particles in all 11 transects showed a tendency towards spatial clustering, i.e. patch formation. Histogram plots of log abundance versus DNE were then constructed for each transect, combining all size classes of particles encountered (Fig. 2).

A random distribution of particles along a transect should produce a single exponential distribution of DNE values (Fig. 2), forming a linear frequency distribution on a log-linear scale (Sokal \& Rohlf 1981). However, the observed DNE frequency distribution plots (Fig. 3) all exhibited 2 distinct regions which would not be expected and which cannot be expressed as a single, simple Poisson distribution. The example plot (Fig. 2) illustrates that the 'first region' of the distribution (at distances between organisms $<0.2 \mathrm{~m}$ ) corresponds rather well to an exponential decrease $\left(\mathrm{r}^{2}=\right.$ 0.89 to 0.97 ) i however, a second distribution is also

\section{RESULTS}

Approximately 200 transects were carried out with the OPC during the 1995 field season. Of these, 11 examples - which were analyzed in detail and in which taxonomic collections were made for calibrating the $\mathrm{OPC}$ are presented here to illustrate the DNE methodology. Taxonomic composition varied somewhat from transect to transect, but 3 basic categories of size distributions can be seen (Fig. 1): predominantly small particles only, <1000 $\mu \mathrm{m}$ ESD (e.g. Fig. 1g, i); small particles with a tail of larger particles, up to $1500 \mu \mathrm{m}$ ESD (e.g. Fig. 1b, c); a mixed size distribution with a greater proportion of large particles up to $2000 \mu \mathrm{m}$ ESD and larger (e.g. Fig. 1a, h). The smallest size category consisted of sea urchin larvae, cladocerans (mainly Evadne sp.), nauplii of calanoid copepods, barnacle nauplius and cypris larvae, and fish eggs. The intermediate size category contained larger nauplii, copepodites of Acartia and Eurytemora, and fish larvae. The largest size category included late stage copepodites, adult copepods, fish larvae, and euphausiid juveniles.

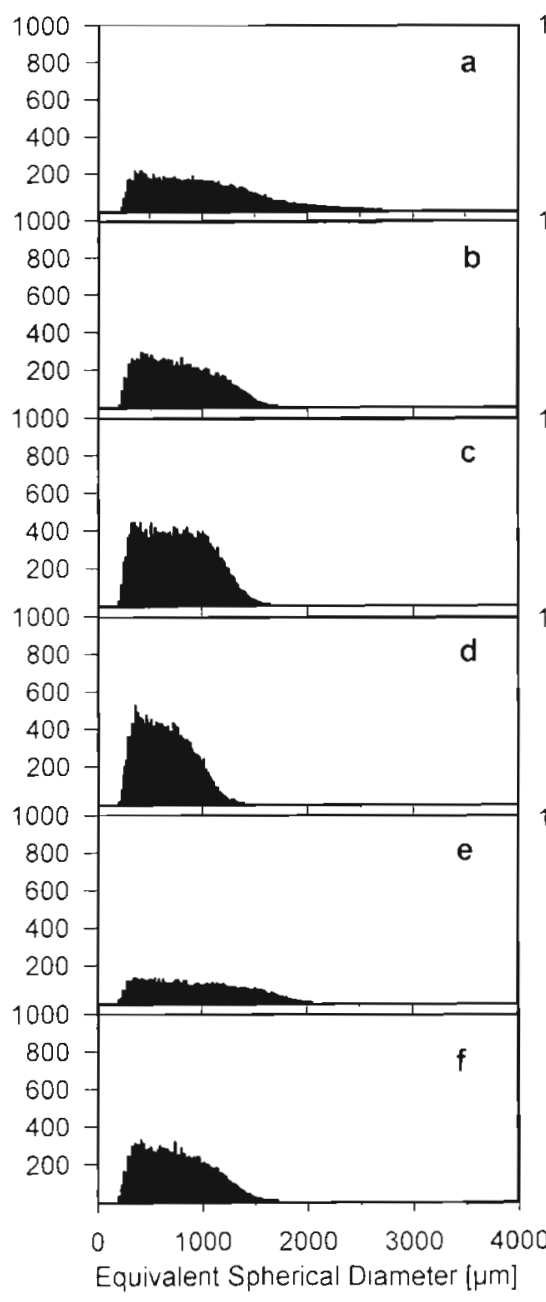

Fig. 1. Size frequency distributions for 11 sampling transects, using an optical plankton counter

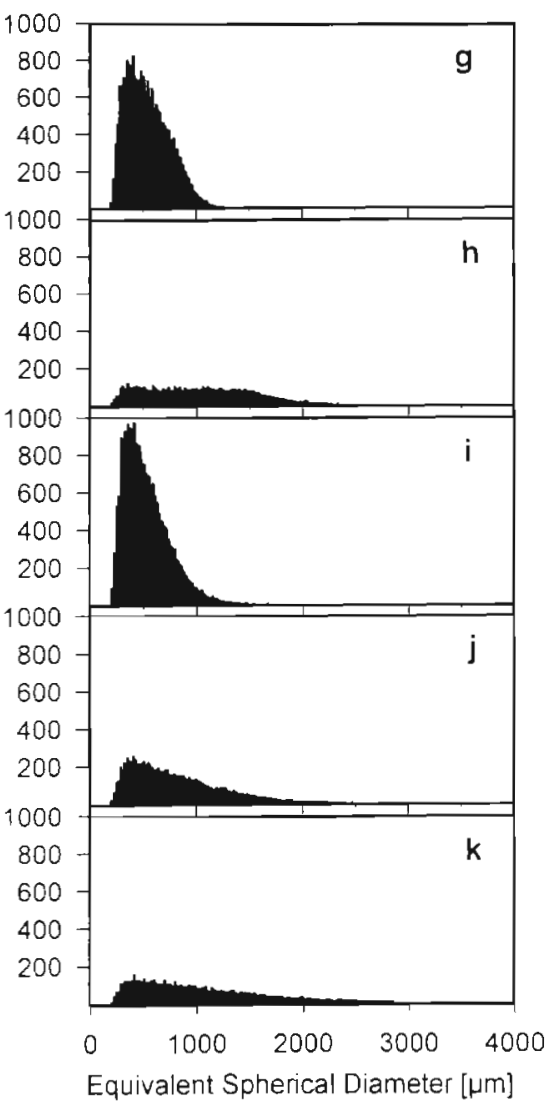


Table 2. Patch statistics calculated using the Distance to Next Encounter technique for 11 transects in 1995 using an Optical Plankton Counter (OPC). The Neighbor statistic (Selkirk \& Neave 1989) for individual zooplankters indicates that all of the transects suggest significant non-randomness $(p<0.0001)$ and clumping, while the distribution of patches indicate non-randomness with a tendency towards regular spacing $(p<0.0001)$

\begin{tabular}{|c|c|c|c|c|c|c|c|c|c|c|c|}
\hline Patch statistic & $\begin{array}{c}16 \mathrm{Jul} \\
\text { (a) }\end{array}$ & $\begin{array}{l}18 \mathrm{Jul} \\
\text { (b) }\end{array}$ & $\begin{array}{l}18 \mathrm{Jul} \\
\text { (c) }\end{array}$ & $\begin{array}{l}25 \mathrm{Jul} \\
\text { (d) }\end{array}$ & $\begin{array}{c}27 \mathrm{Jul} \\
(\mathrm{e})\end{array}$ & $\begin{array}{c}27 \mathrm{JuJ} \\
(\mathrm{f})\end{array}$ & $\begin{array}{l}1 \mathrm{Aug} \\
\text { (g) }\end{array}$ & $\begin{array}{c}2 \mathrm{Aug} \\
\text { (h) }\end{array}$ & $\begin{array}{l}3 \mathrm{Aug} \\
\text { (i) }\end{array}$ & $\begin{array}{c}3 \mathrm{Aug} \\
\text { (j) }\end{array}$ & $\begin{array}{c}3 \mathrm{Aug} \\
\text { (k) }\end{array}$ \\
\hline Total no. of particles, $N$ & 31285 & 28776 & 45647 & 32251 & 18921 & 29187 & 34733 & 17443 & 36563 & 22084 & 18603 \\
\hline Total no. of patches, $n_{4}$ & 487 & 303 & 483 & 344 & 218 & 261 & 318 & 375 & 352 & 231 & 222 \\
\hline No. of patches per $100 \mathrm{~m}, n_{p}$ & 4.04 & 2.76 & 5.49 & 4.55 & 4.18 & 4.56 & 4.49 & 6.65 & 5.53 & 4.63 & 4.60 \\
\hline Total transect distance, $D[\mathrm{~m}]$ & 1205.0 & 1098.5 & 879.4 & 756.7 & 521.0 & 572.5 & 709.0 & 564.1 & 636.9 & 498.7 & 482.8 \\
\hline Total sample volume, $V_{\mathrm{V}}\left[\mathrm{m}^{3}\right]$ & 5.30 & 4.83 & 3.87 & 3.33 & 2.29 & 2.52 & 3.12 & 2.48 & 2.80 & 2.19 & 2.12 \\
\hline Within patch limit, $d_{\operatorname{miax}}[\mathrm{m}]$ & 0.295 & 0.320 & 0.165 & 0.190 & 0.215 & 0.175 & 0.175 & 0.250 & 0.150 & 0.180 & 0.215 \\
\hline Distance occupied by patches, $D_{p}[\mathrm{~m}]$ & 1009.6 & 918.4 & 787.3 & 626.4 & 450.5 & 449.2 & 599.1 & 492.4 & 528.4 & 434.1 & 426.2 \\
\hline No. of particles per patch, $n_{\text {pes }}$ & 64.2 & 35.0 & 94.5 & 93.8 & 86.8 & 111.8 & 109.2 & 46.5 & 103.9 & 95.6 & 83.8 \\
\hline$\%$ transect occupied by patch, $P$. & 83.8 & 83.6 & 89.5 & 82.8 & 86.5 & 78.5 & 84.5 & 87.3 & 82.9 & 87.0 & 88.3 \\
\hline$\%$ gap space, $G$ & 16.2 & 16.4 & 10.5 & 17.2 & 13.5 & 21.5 & 15.5 & 12.7 & 17.1 & 13.0 & 11.7 \\
\hline Mean patch size, $\phi_{p}[\mathrm{~m}]$ & 2.07 & 3.03 & 1.63 & 1.82 & 2.07 & 1.72 & 1.88 & 1.31 & 1.50 & 1.88 & 1.92 \\
\hline Mean spherical patch volume, $V_{p}\left[\mathrm{~m}^{3}\right]$ & 4.67 & 14.58 & 2.27 & 3.16 & 4.62 & 2.67 & 3.50 & 1.19 & 1.77 & 3.48 & 3.71 \\
\hline Density of patch (linear), $\rho_{1}[\mathrm{~m}]$ & 31.0 & 31.3 & 58.0 & 51.5 & 42.0 & 65.0 & 58.0 & 35.4 & 69.2 & 50.9 & 43.6 \\
\hline Patch sampled volume, $V_{3 p}\left[\mathrm{~m}^{3}\right]$ & 0.00912 & 0.0133 & 0.00717 & 0.00801 & 0.00909 & 0.00757 & 0.00829 & 0.00578 & 0.00660 & 0.00827 & 0.00845 \\
\hline Within patch density per $\mathrm{m}^{3}, \rho_{\mathrm{p}}$ & 7040 & 7120 & 13180 & 11700 & 9550 & 14770 & 13180 & 8050 & 15730 & 11560 & 9919 \\
\hline Overall mean density per $\mathrm{m}^{3}, \rho_{\mathrm{t}}$ & 5900 & 5950 & 11800 & 9690 & 8250 & 11590 & 11130 & 7030 & 13050 & 10060 & 8760 \\
\hline Neighbor statistic (individuals) & 0.3855 & 0.3667 & 0.4143 & 0.3782 & 0.3884 & 0.3799 & 0.3946 & 0.4079 & 0.3696 & 0.3733 & 0.3773 \\
\hline Neighbor statistic (patches) & 0.6290 & 0.6481 & 0.6441 & 0.7180 & 0.6538 & 0.6724 & 0.6887 & 0.6202 & 0.7243 & 0.6475 & 0.6065 \\
\hline
\end{tabular}

apparent at scales $>0.2 \mathrm{~m}$. This second distribution, indicating large distances between successive particles, clearly departs from a simple, single exponential distribution. The tail of greater distances, at scales $>0.2 \mathrm{~m}$, indicates that greater DNE values were observed $10^{2}$ to $10^{5}$ times more frequently than expected if due to a random distribution. Thus, within our transects, the greatest probability is that of having the next particle very close, with an exponential decrease in probability of having the next encounter further away. In other words, gap distances follow this exponential distribution. However, at a certain distance threshold there is an unexpected increase in the probability of having this size of gap, far greater than can be explained from a single Poisson distribution (Fig. 3).

If we assume that plankton abundance is patchy, then it follows that the first part of the distribution must reflect the distribution of gaps between particles

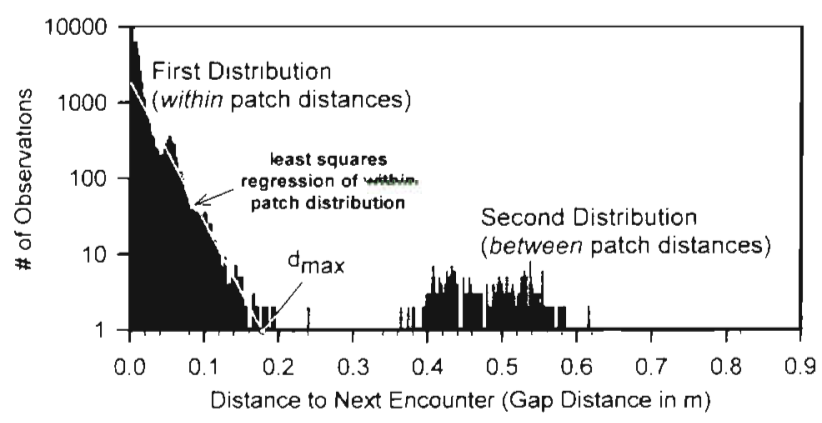

Fig. 2. Illustration of the parts of the log-normal histograms of abundance vs Distance to Next Encounter (DNE) within patches and the second distribution (indicating large inter-particle gaps) corresponds to the distribution of gaps between particles which belong to different patches (the edge of one patch to the beginning edge of the next). The Selkirk \& Neave (1984) neighbor distance statistic, on the distribution of the patches themselves, indicated that the patches were arranged significantly non-randomly $(p<0.0001)$ with a tendency toward non-aggregated (regular) spacing.

The calculation of various descriptors of patchiness now becomes possible. Knowing the surface area of the sampling beam, the length of the profile (sum of the distances between particles) and the number of distributions allows calculation of the percentage of the transect occupied by patches $\left(P_{\%}\right)$ or gaps $\left(G_{\%}\right)$, an estimate of patch size $\left(\phi_{p}\right)$ and patch densities $\left(\rho_{l}, \rho_{p}, \rho_{l}\right)$ as summarized in Table 2.

The limit of the first distribution (within patch) $d_{\max }$, given by the intercept of the line of best fit, varies from 0.17 to $0.34 \mathrm{~m}(0.216 \pm 0.019 \mathrm{SE})$ within these 11 transects. The distance to next patch value of DNE varied from 0.22 to $0.59 \mathrm{~m}$, and the estimated patch size ranged from 1.3 to $3.0 \mathrm{~m}(1.9 \pm 0.13 \mathrm{SE})$ in diameter. We could not clearly find any relationship between the size spectrum of the transects (Fig. 1) and any of the calculated patch statistics such as $d_{\text {max }}$.

Note that the majority of distance along a transect is considered to be within a patch, ranging from 78.4 to $89.5 \%(85.0 \pm 0.95)$. In terms of density estimation, it can be seen that as the percentage of space occupied by patches decreases, the overall average density 


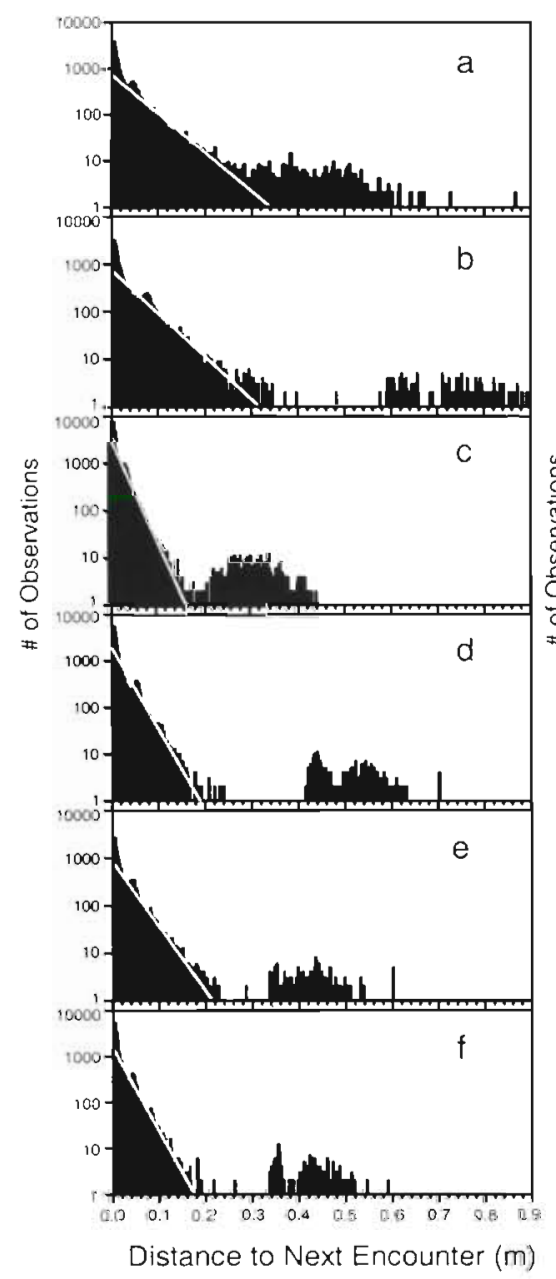

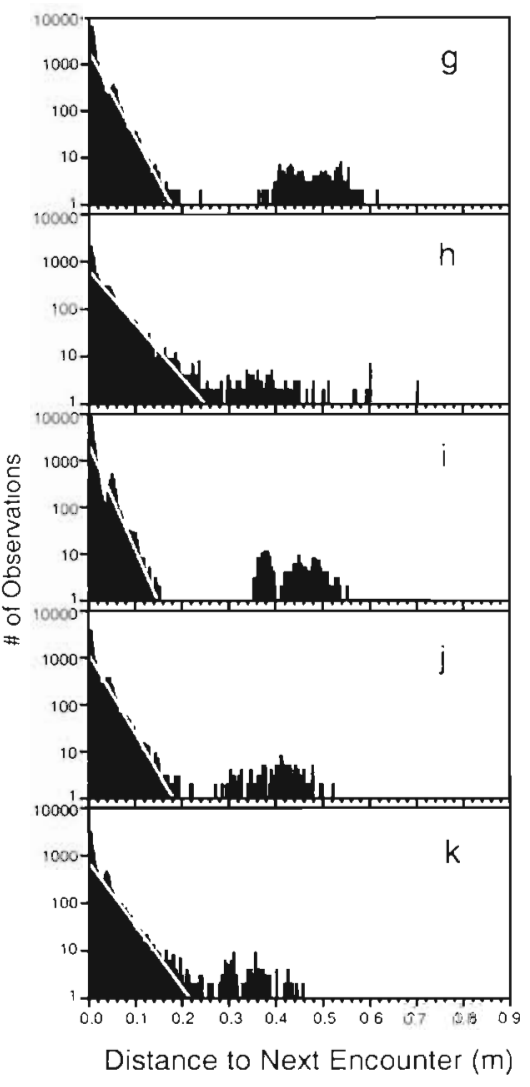

Fig. 3. Log-normal histograms of abundance vs Distance to Next Encounter, for 11 sampling transects munities over a century ago (Haeckel 1891). However if a distribution is patchy, then conventional statistical methods become less useful as analytical tools due to violations in assumptions such as randomness. The neighbor method of Selkirk \& Neave (1984) and our DNE analysis both describe strong patchiness at the meter scale. This extends the existing hierarchy of patchiness in coastal zooplankton populations, which is well documented by conventional techniques at larger scales (Pinel-Alloul 1995), to the meter and centimeter scales.

The 2 sections of the DNE histograms most likely point to different processes. The first pattern (withinpatch: see Fig. 2), characterized by DNE below approximately $0.2 \mathrm{~m}$, is well described by an exponential distribution of gaps; thus, within the patches, the zooplankton are randomly distributed $\left(\mathrm{r}^{2} \approx 0.94\right)$. The second section (between-patch) is the existence of another region in the DNE, at gaps greater than $0.3 \mathrm{~m}$, where the probability of encountering these large gaps is on the order of $10^{2}$ to $10^{5}$ times greater than would be expected given a simple exponential distribution. These 2 patterns thus diminishes proportionally and becomes less accurate as an estimate of within-patch density (see Table 2). For instance, for transect (a), the overall density is 5900.8 organisms $\mathrm{m}^{-3}$, but the within patch density is $7042 \mathrm{~m}^{-3}$ when $P_{\%}$ is $84 \%$. If $P \%$ was $100 \%$ then the entire transect would be considered within a patch, so the overall density would equal the within-patch density. Also, a low value of $d_{\max }$ can lead to very high within-patch densities due to the large slope of the line of best fit. In addition, the wide variation among transects for the estimated densities of organisms within patches $\left(\rho_{p}\right)$ and in the other descriptive statistics allows for quick comparisons between transects. For instance, transects (b) and (f) have a very similar size structure (Fig. 1), yet transect (f) has more than twice the within-patch density $\left(\rho_{p}\right)$ of transect (b).

\section{DISCUSSION}

The recognition of patchiness is hardly new to plankton ecology; it was described within zooplankton com- define both the gaps between zooplankton within patches at the micro-scale, and the gaps of rarefied abundances between the patches themselves.

Elongation or iteration of the 'second' distribution, at scales above $1 \mathrm{~m}$, might be expected on the DNE histograms given a large enough sample size. These would represent iterations of the patchy distributions that may or may not be fractal. However, given our high zooplankton densities, the probability of encountering a gap greater than $1 \mathrm{~m}$ (no particles encountered) becomes infinitesimally small. In very long transects which record approximately 1 million particles, only rarely do we see many gaps greater than $1.5 \mathrm{~m}$.

For the present, the structure of the gaps can be well described, but the structure of the patches themselves requires additional exploration with alternative techniques. Our technique produces an estimate of patch size, but uses an assumption of a regular distribution of patches. This assumption is in fact reasonable, based on the evidence from the neighbor statistic of the patches themselves, which suggested a tendency toward non-aggregated (regular) spacing (Table 2). This 
is then perhaps a good first approximation of patch density, but it is obvious that it is not sufficient description of the patch pattern. A preliminary analysis of the distribution of biomass within and between patches is in progress, and suggests that the combined influence of particle numbers and particle size leads to a fractal pattern of biomass

Neither the mechanism favoring generation of gaps and patches within the zooplankton, nor the processes underlying their apparent random distribution within patches, are yet clear. Some coupling of swimming behavior of the animals with micro-scale turbulence of water motion seems implicated. In our environment, this coupling may represent the lower scale limit of turbulent effects on zooplankton distributions, and is currently under investigation.

Our evidence of the existence of zooplankton patches, but random distributions within the patches themselves, has implications for some of the newer foraging models concerning zooplankton. These models tend to generate and use aggregations of zooplankton which may be considerably more influenced by turbulence than those observed within our data (Rothschild \& Osborn 1988, Mackenzie \& Leggett 1991, Yamazaki et al. 1991, Kiørboe \& Saiz 1995, Landry et al. 1995). This will also change the nature of the food signal these models represent. Planktonic animals have been shown to remain within patches when feeding (Price 1989), or exhibit more fine-scale movements in areas of higher food concentration (Bundy et al. 1993, Cuddington \& McCauley 1994). Thus encounter rates might actually be best described using a simple model of random encounter when feeding within patches (intensive search), yet they could be considerably different during the search for new patches (extensive search) as has been described in the foraging behavior of beetles (Ferran \& Dixon 1993). Foraging models will likely have to incorporate switching between feeding and searching behaviors as scaled to the organism size, in order to effectively simulate these complex physical-biological relationships (Noda et al. 1992).

There now exist a variety of instruments for quantification of zooplankton abundances at high resolution, some of which allow organism identification (e.g. Hardy continuous plankton recorder, Video Plankton Recorders) (Dickey 1988, Weibe et al. 1992). Given the application history of size spectra in the pelagic ocean (Sheldon et al. 1972), the lack of taxonomic information collected by the OPC is more than compensated for by the high spatial resolution ( $2 \mathrm{~mm}$ ), ease of deployment, cost in terms of both physical and labor dollars, and the large number of transects that can be rapidly sampled and processed.

The OPC is steadily increasing in use, but it is still generally used only as a size-distribution probe.
Higher quality information can be gathered from this instrument, permitting generation of high resolution in situ data on spatial distribution of zooplankton. The OPC is one of the few oceanographic instruments that can collect biological information on large scale distributions without compromising high resolution data at the small spatial scales. This is important because investigating a phenomenon at extremely small scales often hampers our understanding of larger scale patterns, due to physical data storage limitations, the complex analysis of large data sets, and mere statistics.

Patchy distributions, even at scales well below the sampling resolution of most devices (nets, plankton recorder, etc.) indicate the need for adaptive sampling strategies. The OPC is accommodating in this sense because processing of the data can be done at almost any (or all) scales; this allows the use of statistical methods of analysis (e.g. on biomass estimates) when investigating larger scales of distribution. Comparison of zooplankton distribution data to the synchronously gathered physical oceanographic measurements from the CTD or ADCP is also possible, and will hopefully shed light on the mechanisms underlying zooplankton patchiness over a range of scales. Unfortunately at this time, the sampling resolution of the CTD $(4$ to $24 \mathrm{~Hz}$ in recent models) and $A D C P$ is still coarser than the OPC. This puts biological oceanographers in the unfamiliar position of having the capability to gather information at a higher resolution than their physical oceanographer colleagues.

Acknowledgements. We thank Jeff Runge and Michel Boule for their technical assistance and use of their OPC. Thanks to the GIROQ, and especially Jean-Yves Anctil for equipment maintenance and Guy Millet for emergency late night repairs. The aid of our captains, Daniel Saint-Pierre and Martin Lévêque, and crew, Heather Brunstad and Kim Rose, was much appreciated. This is a contribution to the C.H.A.S.E. project; we thank the members of the group for their insights and stimulating discussions. Funding was provided by an NSERC Canada Strategic grant to E. Bourget, G. Ingram, S. Lovejoy and J.C.R., and NSERC Canadà Operating grants to J.C.R.

\section{LITERATURE CITED}

Bundy MH, Gross TF, Coughlin DJ, Strickler JR (1993) Quantifyng copepod searching efficiency using swimming pattern and perceptive ability. Bull Mar Sci 53:15-28

Cuddington KM, McCauley E (1994) Food-dependent aggregation and mobility of the water fleas Ceriodaphnia dubia and Daphnia pulex. Can J Zool 72:1217-1226

Davis CS, Flierl GR, Wiebe PH, Franks PJS (1991) Micropatchiness, turbulence and recruitment in plankton. J Mar Res 49:109-151

Davis CS, Gallager SM, Solow A (1992) Microaggregations of oceanic plankton observed by towed video microscopy. Science 257:230-232

Dickey TD (1988) Recent advances and future directrons in multi-disciplinary in situ oceanographic measurement 
systems. In: Rothschild BJ (ed) Toward a theory on biological-physical interactions in the world ocean. Kluwer Academic, Dordrecht, p 555-598

Ferran A, Dixon AFG (1993) Foraging behaviour of ladybird larvae (Coleoptera: Coccinellidae). Eur J Entomol 90: $383-402$

Franks PJS (1992) Sink or swim: accumulation of biomass at fronts. Mar Ecol Prog Ser 82:1-12

Greig-Smith P (1964) Quantitative plant ecology. Butterworths, New York

Haeckel E (1891) Plankton Studien. Jena Zt Naturwissensch 25:232-336

Haury LR, Yamazaki H, Fey CL. (1992) Simultaneous measurements of small-scale physical dynamics and zooplankton distributions. J Plankton Res 14:513-530

Herman AW, Cochrane N, Sameoto DD (1992) Design and calibration of a new optical plankton counter capable of sizing small zooplankton. Deep-Sea Res 39:395-415

Hill AE (1991) A mechanism for horizontal zooplankton transport by vertical migration in tidal current. Mar Biol 111 485-492

Hwang JS, Costello JH, Strickler JR (1994) Copepod grazing in turbulent flow: elevated foraging behaviour and habituation of escape response. J Plankton Res 16:421-431

Kiørboe T, Saiz E (1995) Planktivorous feeding in calm and turbulent environments, with emphasis on copepods. Mar Ecol Prog Ser 122:135-145

Landry F, Miller TJ, Leggett WC (1995) The effects of smallscale turbulence on the ingestion rate of fathead minnow (Pimephales promelas) larvae. Can J Fish Aquat Sci 52 $1714-1719$

Lazier JRN, Mann KH (1989) Turbulence and the diffusive layers around small organisms. Deep-Sea Res 36: $1721-1733$

Ledbetter M (1979) Langmuir circulations and plankton patchiness. Ecol Model 7:289-310

Leising AW, Yen J (1997) Spacing mechanisms within lightinduced copepod swarms. Mar Ecol Prog Ser 155:127-135

MacKenzie BR, Leggett WC (1991) Quantifying the contribution of small-scale turbulence to the encounter rates between larval fish and their zooplankton prey: effects of wind and tide. Mar Ecol Prog Ser 73:149-160

Noda M, Kawabata K, Gushima K, Kakuda S (1992) Importance of zooplankton patches in foraging ecology of the planktivorous fish Chromis chrysurus (Pomacentridae) at Kuchinoerabu Island, Japan. Mar Ecol Prog Ser 87:251-263

Osborn TR, Yamasaki H. Squires K (1990) Direct simulation of the effect of turbulence on planktonic contact rates. In:

Editorial responsibility: Otto Kunne (Editor)

Oldendorf/Luhe, Germany
Sherman K, Alexander LM, Gold BD (eds) Large marine ecosystems: patterns, processes, and yields. American Association for the Advancement of Science, Washington, DC, p 99-103

Pielou EC (1969) An introduction to mathematical ecology Wiley, Toronto

Pinel-Alloul B (1995) Spatial heterogeneity as a multiscale characteristic of zooplankton community. Hydrobiologia $300-301: 17-42$

Price HJ (1989) Swimming behavior of krill in response to algal patches: a mesocosm study. Limnol Oceanogr 34 $649-659$

Riley GA (1976) A model of plankton patchiness. Limnol Oceanogr 21:873-879

Rothschild BJ (1992) Application of stochastic geometry to problems in plankton ecology. Phil Trans R Soc Lond B 336:225-237

Rothschild BJ, Osborn TR (1988) Small-scale turbulence and plankton contact rates. J Plankton Res 10:465-474

Schneider DC, Bajdik CD (1992) Decay of zooplankton patchiness generated at the sea surface. J Plankton Res 14: $531-543$

Selkirk KE, Neave HR (1984) Nearest-neighbour analysis of one-dimensional distributions of points. Tijdschr Econ Soc Geogr 75:356-362

Shanks AL (1983) Surface slicks associated with tidally forced waves may transport pelagic larvae of benthic invertebrates and fishes shoreward. Mar Ecol Prog Ser 13:311-315

Sheldon RW, Prakash A, Sutcliffe WH Jr (1972) The size distribution of particles in the ocean. Limnol Oceanogr 17: $327-340$

Shiyomi M. Yamamura K (1993) Spatıal pattern indices based on distances between individuals on a line-segment with finite length. Res Popul Ecol 34:321-330

Sokal RR, Rohlf FJ (1981) Biometry. WH Freeman, New York

Southwood TRE (1978) Ecological methods: with particular reference to the study of insect populations. Wiley, Toronto

Weibe $\mathrm{PH}$, Davis $\mathrm{CS}$, Greene $\mathrm{CH}$ (1992) Visualizing life in the ocean interior: instruments for probing the depths Oceanus 35(3):100-106

Weingart M, Selvin S (1995) Nearest neighbor analysis in one-dimension. Report LBL-36888, Lawrence Berkeley National Laboratory, Berkeley

Yamazaki H, Haury LR (1993) A new Lagrangian model to study animal aggregation. Ecol Model 69:99-111

Yamazaki H, Osborn TR, Squires KD (1991) Direct numerical simulation of planktonic contact in turbulent flow. J Plankton Res 13:629-643

Submitted: February 2, 1998; Accepted: July 9, 1998

Proofs received from author(s): September 8, 1998 